\title{
Comparison of intravenous hydralazine and intravenous labetalol in the management of severe hypertensive disorders of pregnancy: a tertiary care centre study
}

\author{
Manvi Verma*, Shashi Gupta, B. R. Bhagat, Aakanksha Mahajan, Baseerat Kaur
}

Department of Obstetrics and Gynecology, SMGS Hospital, GMC Jammu, Jammu and Kashmir, India

Received: 18 March 2018

Accepted: 21 April 2018

*Correspondence:

Dr. Manvi Verma,

E-mail: manvi278@gmail.com

Copyright: () the author(s), publisher and licensee Medip Academy. This is an open-access article distributed under the terms of the Creative Commons Attribution Non-Commercial License, which permits unrestricted non-commercial use, distribution, and reproduction in any medium, provided the original work is properly cited.

\begin{abstract}
Background: Severe hypertension in pregnancy (SBP $\geq 160 \mathrm{mmHg} \& /$ or DBP $\geq 110 \mathrm{mmHg}$ ) must be treated judiciously to prevent maternal and fetal complications. The study was conducted to compare the efficacy, adverse effects, maternal and fetal outcome between Hydralazine and Labetalol which are the most commonly used drugs for the purpose.

Methods: In a prospective study, 130 pregnant patients each with severe hypertension presenting to SMGS Hospital Jammu were randomized in 2 groups and administered hydralazine or labetalol intravenously. The efficacy of the two drugs was measured in terms of number of doses required to obtain target BP and the timing to achieve the same. The incidence of adverse effects, maternal and fetal outcomes were also compared. Comparisons among the two groups was performed by using independent Student's t test for normally distributed variables, Fishers' exact test, and Pearson Chi Square test for categorical variables. The level of significance was set at $\mathrm{p}<0.05$ for all analysis.

Results: There was no statistical difference between the two drugs in terms of efficacy. Significantly more low-birth weight infants were born in the hydralazine group. Also, the adverse effects were significantly more in the hydralazine group.

Conclusions: Both hydralazine and labetalol can be used to treat hypertensive emergencies of pregnancy but hydralazine is associated with more side effects.
\end{abstract}

Keywords: Hydralazine, Hypertensive disorders of pregnancy, Labetalol

\section{INTRODUCTION}

Hypertensive disorders complicate 5 to 10 per cent of all pregnancies, and together they are one member of the deadly triad along with haemorrhage and infection that contributes greatly to maternal morbidity and mortality. Of these disorders, the pre-eclampsia syndrome, either alone or superimposed on chronic hypertension, is the most dangerous. ${ }^{1}$ Although, there is a lack of agreement regarding the blood pressure levels at which to initiate antihypertensive therapy, there is no debate that severe hypertension (i.e. systolic pressure $>160 \mathrm{mmHg}$ and /or diastolic pressure $>110 \mathrm{mmHg}$ ) should be treated to prevent maternal and the consequent fetal complications. ${ }^{2}$ Women with pre-eclampsia, without differentiating the severity of the disease, are predisposed to develop complications such as abruptio placentae, disseminated intravascular coagulation, cardiopulmonary complications (pulmonary edema), cerebral hemorrhage, hepatic rupture, hepatic insufficiency and death. The fetal complications are the reduction of the oxygen and nutrient supply leading to fetal growth restriction (FGR), 
low birth weight infants or small for gestational age (SGA) infants, prematurity, increased risk of developing acute and chronic lung diseases from birth to fetal or neonatal death, as well as hypertension and dyslipidemia early in adulthood (Barker theory). ${ }^{3}$ Hydralazine and labetalol are the most commonly used drugs in the treatment of hypertensive emergencies of pregnancy. The objective of this study is to compare the efficacy of intravenous hydralazine and intravenous labetalol in the control of blood pressure in severe hypertensive disorders of pregnancy and to compare the adverse effects, maternal outcome and fetal outcome between the two groups.

\section{METHODS}

A prospective single blinded randomized study was conducted in the Post Graduate department of Obstetrics \& Gynaecology, Shri Maharaja Gulab Singh (SMGS) Hospital, Government Medical College, Jammu from October 2016 to September 2017. 130 consecutive patients with severe hypertension were selected (systolic blood pressure $\geq 160 \mathrm{mmHg} \& /$ or Diastolic Blood Pressure $\geq 110 \mathrm{mmHg}$ ) after obtaining approval from the institutional ethical committee (IEC). Inclusion and exclusion criteria were applied. Patients were randomized in 2 groups, each consisting of 65 patients. The inclusion criteria were patients with SBP $\geq 160$ \&/or DBP $\geq 110$ $\mathrm{mmHg}$, single pregnancy, gestational age $\geq 24$ weeks, no contraindication to the use of hydralazine or labetalol and haemodynamically stable patient. Exclusion criteria were contraindications to hydralazine or labetalol and patients with established target end organ damage. Informed consent was obtained from the patient or from attendant if she was not conscious.

A structured proforma was used to assess the patient as per which, patient's demographics, chief complaints and medical history was recorded. Detailed general physical examination and local examination was performed.

The sample size for comparison groups was calculated using the formula $n=2 Z^{2} P Q / D^{2}(n=$ minimum sample size, $\mathrm{Z}=95 \%$ confidence interval using $1.96, \mathrm{P}=$ Prevalence of severe pre-eclampsia (2.0), $\mathrm{Q}=1.0-\mathrm{P}, \mathrm{D}=$ degree of accuracy desired, set at $0.05, \mathrm{n}=60 .{ }^{4}$ By adding $5 \%$ attrition rate and anticipating response rate of $95 \%$, the minimum selected sample size was calculated as $60 / 0.95=63$. Each trial group was allocated 65 participants who were administered hydralazine or labetalol intravenously.

Baseline blood pressure measured by means of a standardised sphygmomanometer was recorded in the left lateral recumbent position. The patients were randomly assigned by lottery method to two groups, every time such patient was admitted to labour room till the desired sample size was achieved in both the groups.
The Hydralazine group (Group A) received $5 \mathrm{mg}$ as initial I/V bolus (slowly over $5 \mathrm{mins}$ ). The $(5 \mathrm{mg})$ dose was repeated every 15 minutes until the target blood pressure (SBP $\leq 150$ \&/or DBP $\leq 100 \mathrm{~mm} \mathrm{Hg}$ ) was achieved. The dose was limited to a maximum of 3 doses. The Labetalol Group (Group B) received $20 \mathrm{mg}$ as initial $\mathrm{I} / \mathrm{V}$ bolus (slowly over $10 \mathrm{~min}$ ). Blood pressure was measured every 15 minutes to observe effect of drug. 40 $\mathrm{mg}$ of labetalol was administered as the second dose if target blood pressure was not achieved. Another $80 \mathrm{mg}$ was administered which could be repeated two times more till a maximum dose of $300 \mathrm{mg}$ was administered (upto total 5 doses). In both the groups if the blood pressure was not controlled even after the maximum dose thus defined was reached, oral Nifedipine $(10 \mathrm{mg})$ every 15 minutes until control of the crises (upto a maximum of 5 doses) was used. All data was compared in the tables as Mean $\pm S D$, absolute values (percentage), or relative number of patients. Comparisons for demographic and clinical variables among the two groups was performed by using independent Student's t test for normally distributed variables, Fishers' exact test, and Pearson Chi Square test was used for categorical variables to analyse the data. The level of significance was set at $p<0.05$ for all analysis.

The primary outcome measured was the efficacy of the medication (minimum number of doses required to obtain an adequate control of $\mathrm{BP}$ (SBP $\leq 150$ \&/or DBP $\leq 100$ $\mathrm{mm} \mathrm{Hg}$ ) and the timing to achieve control of BP.

The secondary outcome measured was the incidence of adverse effects, maternal and fetal outcomes. The maternal parameters which were compared included control of hypertensive crises, mode of delivery, gestational age at delivery, occurrence of eclampsia, HELLP syndrome, placental abruption, admission in ICU and maternal mortality. The fetal parameters which were compared included fetal maturity, birth weight, APGAR scores at $1 \mathrm{~min} \& 5 \mathrm{~min}$, fetal distress, admission in NICU, occurrence of IUD and IUGR.

\section{RESULTS}

A total of 130 women meeting the inclusion criteria were included in the study. The baseline variables were similar in women in both groups (Table 1).

Mean number of doses required to achieve control of blood pressure in Group A was $1.82 \pm 0.80$ (with a range of 1 to 3 doses) as compared to $1.98 \pm 1.17$ in Group B (with a range of 1 to 5 doses) which was found to be statistically non-significant $(\mathrm{p}=0.38)$ (Table 2).

Mean duration of time required to achieve blood pressure control in Group A was 27.33 \pm 12.0 minutes with a range of 15-45 minutes while it was $29.74 \pm 17.65$ minutes in Group B with a range of 15-75 minutes which was found to be statistically non-significant $(\mathrm{p}=0.38)$ (Table 3). 
There were 3 treatment failures in hydralazine group and 7 treatment failures in the labetalol group.

Table 1: Baseline variables.

\begin{tabular}{|lll|}
\hline & Group A & Group B \\
\hline Mean age & $26.75 \pm 5.21$ & $26.26 \pm 4.08$ \\
\hline Primigravida & $38(58.46)$ & $37(56.92)$ \\
\hline Multigravida & $27(41.53)$ & $28(43.07)$ \\
\hline Lower class & $16(24.61)$ & $15(23.07)$ \\
\hline Rural residence & $40(61.53)$ & $35(53.84)$ \\
\hline Urban residence & $25(38.46)$ & $30(46.15)$ \\
\hline $\begin{array}{l}\text { Pre-exististing } \\
\text { hypertension }\end{array}$ & $29(44.61)$ & $18(27.69)$ \\
\hline
\end{tabular}

$\mathrm{P}>0.05$, not significant.

Table 2: Mean number of doses required to achieve control of blood pressure.

\begin{tabular}{|lll|}
\hline $\begin{array}{l}\text { Study } \\
\text { groups }\end{array}$ & $\begin{array}{l}\text { Number of } \\
\text { doses } \\
\text { Mean } \pm \text { SD }\end{array}$ & $\begin{array}{l}\text { Statistical } \\
\text { inference } \\
\text { (Unpaired ' } t \text { ' test) }\end{array}$ \\
\hline $\begin{array}{l}\text { Group A } \\
\mathrm{n}=62 *\end{array}$ & $\begin{array}{l}1.82 \pm 0.80 \\
(\text { Range }, 1-3)\end{array}$ \\
\hline $\begin{array}{l}\text { Group B } \\
\mathrm{n}=58^{* *}\end{array}$ & $\begin{array}{l}1.98 \pm 1.17 \\
\text { (Range, } 1-5)\end{array}$ \\
\hline
\end{tabular}

*3 patients required nifedipine **7 Patients required nifedipine NS=Not Significant

Table 3: Mean duration of time required to achieve control of blood pressure.

\begin{tabular}{|lll|}
\hline $\begin{array}{l}\text { Study } \\
\text { groups }\end{array}$ & $\begin{array}{l}\text { Mean } \pm \text { SD } \\
\text { (Time } \\
\text { required in } \\
\text { minutes) }\end{array}$ & $\begin{array}{l}\text { Statistical } \\
\text { inference } \\
\text { (Unpaired ' } t \text { ' test) }\end{array}$ \\
\hline $\begin{array}{l}\text { Group A } \\
\mathrm{N}=62 *\end{array}$ & $\begin{array}{l}27.33 \pm 12.0 \\
\text { (Range, } 15-45)\end{array}$ \\
\hline $\begin{array}{l}\text { Group } \mathrm{B} \\
\mathrm{N}=58 * *\end{array}$ & $\begin{array}{l}29.74 \pm 17.65 \\
\text { (Range, } 15-75)\end{array}$ \\
\hline
\end{tabular}

$* 3$ patients required nifedipine $* * 7$ Patients required nifedipine NS=Not Significant.
$47.69 \%$ (31) patients in Group A had adverse effects as compared to $23.07 \%(15)$ patients in Group B and this difference was highly significant $(\mathrm{p}=0.005) .12 .30 \%(8)$ patients in Group A and 6.15\%(4) patients in Group B had more than one adverse effect. There were 39 and 20 adverse effects in total in Group A \& Group B respectively and this difference was highly significant statistically $(\mathrm{p}=0.001)$. Headache was observed more significantly in Group A compared to Group B ( $\mathrm{p}=0.035)$. The rest of adverse effects like tachycardia, palpitations, flushing, nausea/vomiting, epigastric pain, visual disturbances, dizziness were mild and no statistical difference between the two groups was observed $(p>0.05)$ (Table 4).

$47.69 \%(31)$ patients versus $46.15 \%(30)$ patients delivered vaginally and $52.30 \%$ (34) patients versus $53.84 \%$ (35) patients delivered by cesarean section in Group A \& Group B respectively, the difference was not statistically significant. $10.76 \%$ (7) and $4.61 \%$ (3) patients in Group A \& B respectively had adverse outcome, the difference was not significant statistically. $47.69 \%$ (31) and $23.07 \%$ (15) patients in Group A \& B respectively had adverse effects and the difference was highly significant $(\mathrm{p}=0.005)$ (Table 5).

$40 \%$ (26) and $29.23 \%$ (19) neonates were low birth weight in Group A \& B respectively, $15.38 \%$ (10) and $6.15 \%$ (4) neonates were extremely low birth weight in Group A \& B respectively. The difference between the two groups was significant $(\mathrm{p}=0.03) .10 .76 \%$ (7) and $4.61 \%$ (3) neonates had APGAR score less than 7 at 1 minute of birth, whereas $6.15 \%$ (4) neonates and $1.53 \%(1)$ neonate had APGAR score less than 7 at 5 minutes of birth in Group A \& B respectively. The difference between the two groups was not significant. $20 \%$ (13) and $24.61 \%$ (16) neonates were admitted in NICU in Group A \&B respectively, the difference was not significant. There were $13.84 \%$ (9) and $9.23 \%$ (6) neonatal mortalities in Groups A \& B respectively and the difference was not significant statistically (Table 6).

Table 4: Adverse effects of drugs.

\begin{tabular}{|lllllll|}
\hline \multirow{2}{*}{ Adverse effects of drugs } & \multicolumn{2}{l}{ Group A } & \multicolumn{2}{l|}{ Group B } & $\begin{array}{l}\text { Statistical Inference } \\
\text { (Fisher exact test) }\end{array}$ & SIG \\
\cline { 2 - 7 } & No. & $\%$ & No. & $\%$ & p value & S \\
\hline Headache & 15 & 38.46 & 2 & 10 & 0.035 & NS \\
\hline Tachycardia & 6 & 15.38 & 1 & 5 & 0.40 & \\
\hline Palpitations & 5 & 12.82 & 4 & 20 & & \\
\hline Flushing & 2 & 5.12 & 3 & 15 & & \\
\hline Nausea/vomiting & 3 & 7.69 & 2 & 10 & & \\
\hline Epigastric pain & 3 & 7.69 & 1 & 5 & & \\
\hline Visual Disturbances & 2 & 5.12 & 3 & 15 & & HS \\
\hline Dizziness & 2 & 5.12 & 2 & 10 & & \\
\hline Others & 1 & 2.56 & 2 & 10 & & \\
\hline Total & 39 & 100.00 & 20 & 100.00 & 0.001 & \\
\hline
\end{tabular}

$\mathrm{S}=$ Significant; NS= Not Significant; HS= Highly Significant. 
Table 5: Maternal outcome.

\begin{tabular}{|ll|lll|}
\hline S.NO. & & Group A & Group B & Significance \\
\hline 1 & Mode of delivery & No. $(\%)$ & No. $(\%)$ & \multirow{2}{*}{ NS } \\
\hline & Vaginal & $31(47.69)$ & $30(46.15)$ & NS \\
\hline & Cesarean & $34(52.30)$ & $35(53.84)$ & HS (p=0.005) \\
\hline 2 & Adverse outcome & $7(10.76)$ & $3(4.61)$ & $15(23.07)$ \\
\hline 3 & Adverse effects & $31(47.69)$ & & \\
\hline
\end{tabular}

NS=Not significant; HS=Highly Significant.

Table 6: Fetal outcome.

\begin{tabular}{|c|c|c|c|c|}
\hline S.no. & Birth weight & $\begin{array}{l}\text { Group A } \\
\text { No. (\%) }\end{array}$ & $\begin{array}{l}\text { Group B } \\
\text { No. (\%) }\end{array}$ & Significance \\
\hline \multirow{2}{*}{1} & LBW & $26(40)$ & $19(29.23)$ & \multirow{2}{*}{$\mathrm{S}(\mathrm{p}=0.03)$} \\
\hline & ELBW & $10(15.38)$ & $4(6.15)$ & \\
\hline \multirow{3}{*}{2} & APGAR score & & & \multirow{3}{*}{ NS } \\
\hline & $<7$ at $1 \mathrm{~min}$ & $7(10.76)$ & $3(4.61)$ & \\
\hline & $<7$ at $5 \mathrm{~min}$ & $4(6.15)$ & $1(1.53)$ & \\
\hline 3 & NICU admission & $13(20)$ & $16(24.61)$ & NS \\
\hline 4 & Stillbirths/IUD & $9(13.84)$ & $6(9.23)$ & NS \\
\hline
\end{tabular}

NS=Not significant; $S=$ Significant; HS=Highly Significant

\section{DISCUSSION}

In the present study, the mean number of doses required to achieve control of blood pressure was $1.82 \pm 0.80$ (Range 1-3) in Group A and 1.98 \pm 1.17 (Range 1-5) in Group B and the difference was not significant $(\mathrm{p}=0.38)$.

Mean duration of time required to achieve blood pressure control in patients of Hydralazine group was 27.33 \pm 12.0 (Range 15-45) minutes, while in case of Labetalol group it was 29.74 \pm 17.65 (Range 15-75) minutes. The difference between the two groups was statistically not significant $(\mathrm{p}=0.38)$.

A Cochrane review (2006) failed to judge superiority of either hydralazine or labetalol because of insufficient evidence. In a meta-analysis conducted by Duley et al again insufficient data was found for drawing reliable conclusions about the comparative effects of Hydralazine and Labetalol. They concluded that until better evidence is available, the choice of antihypertensive should depend on what is known about adverse drug effects and how familiar the clinician is with use of a particular drug. ${ }^{5}$

Tabasi et al also found the two drugs to be similar in the control of hypertension. ${ }^{6}$

In study by De Pasquale et al the number of doses to achieve control of blood pressure was 1.4 and 1.3 in Hydralazine and Labetalol groups respectively and the difference was not significant $(\mathrm{p}=0.25){ }^{7}$ Nombur et al also found no significant difference in timing $(\mathrm{p}=0.17)$ and the number of doses $(p=0.94)$ to achieve blood pressure control between the 2 groups. ${ }^{8}$ Similar results were obtained by Nabanita et al (2016) who found no statistical significance in either the number of doses or time required to achieve blood pressure control $(\mathrm{p}=0.94$ and 0.40 respectively) between hydralazine and labetalol groups. ${ }^{9}$

In the study by Khan et al better blood pressure control has been observed with the use of labetalol. This study was conducted in 78 patients and further studies are needed in a larger number of patients to ascertain the superiority of one drug over another. ${ }^{10}$

Mable et al and Ashe et al observed that blood pressure control was achieved with less number of doses and in shorter span of time in hydralazine group as compared to labetalol group. ${ }^{11,12}$

47.69\% (31) patients in Group A had adverse effects compared to $23.07 \%$ (15) patients in Group B. The difference was highly significant $(\mathrm{p}=0.005)$. Headache was seen more frequently in Group $\mathrm{A}$ as compared to Group B and the difference was significant $(p=0.03)$. The other adverse effects observed were tachycardia, palpitations, flushing, nausea/vomiting, epigastric pain, visual disturbances and dizziness which had no statistically significant difference between the two groups. However all adverse effects were mild and not clinically significant.

Vigil-De Gracia et al reported a higher frequency of maternal tachycardia and palpitations with the use of hydralazine compared to the use of labetalol which was similar to the present study, but they observed no 
statistically significant difference in frequency of headache between hydralazine and labetalol groups. ${ }^{13}$

Delgado De Pasquale et al showed no statistically significant difference between hydralazine and labetalol groups in the frequency of adverse reactions. ${ }^{7}$ Similar to present study, headache was more frequently observed in the hydralazine group compared to labetalol in the study by Nombur et al. ${ }^{8}$

Deka Nabanita et al also reported a greater frequency of headache with hydralazine compared to labetalol.

In study conducted by Khan et al patients in Hydralazine group had headache and tachycardia more often as compared to women in Labetalol group. ${ }^{10}$ Side effects like maternal hypotension, nausea, vomiting, adverse fetal heart rate recording were not observed to be significant in either group.

However in a meta-analysis by Magee et al hydralazine was associated with more maternal hypotension, caesarean sections, placental abruption, maternal oliguria, more adverse effects on fetal heart rate and more low APGAR scores at one minute as compared with labetalol and nifedipine. ${ }^{14}$

$10.76 \%$ patients in Group A and $4.61 \%$ patients in Group $\mathrm{B}$ had adverse maternal outcome which included placental abruption, eclampsia and ICU admission. The difference between the two groups was not significant. $44.61 \%$ neonates had normal birth weight in Group A in comparison with $64.61 \%$ neonates in Group B and $40 \%$ had low birth weight in Group A as compared to $29.23 \%$ in Group B. $15.38 \%$ neonates had extremely low birth weight in Group A compared to $6.15 \%$ in Group B. The difference between the two groups was significant $(p=0.03)$. This finding is different from the studies conducted by De Gracia et al, Tabasi et al, Nombur LI et al and Nabanita et al where no significant differences were observed in the fetal outcome in both the groups. ${ }^{6,8,9,13}$

\section{CONCLUSION}

The present study has compared parenteral Hydralazine and Labetalol in control of severe hypertensive disorders of pregnancy and no difference in the efficacy of two drugs was found.

Adverse effects and low birth weight neonates were found more often with Hydralazine. Selection of a better drug between these two is a subject to debate till date and more evidence is needed to label one drug as being superior over another. Presently, choice between the two depends on the availability, the clinical experience of the drug usage and the cost. The present study has added further evidence in the existing literature on the subject.

\section{ACKNOWLEDGMENTS}

Authors would like to thank all patients for their cooperation.

Funding: No funding sources

Conflict of interest: None declared

Ethical approval: The study was approved by the Institutional Ethics Committee

\section{REFERENCES}

1. Cunningham, Leveno, Bloom, Spong, Dashe, Hoffman, Casey, Sheffield, eds. Hypertensive disorders in : Williams Obstetrics, McGraw-Hill education. 24ed. USA; 2014: 728-761.

2. Singh BW, Misra R. Hypertensive Disorders. In: Misra R, ed. Ian Donald's Practical Obstetric Problems, 7 ed, vol. 8. Wolters Kluwer Pvt Ltd; 2014; 142-175.

3. Neto CN, de Souza AS, Amorim MM. Pre-eclampsia treatment According to scientific evidence. J obstet Gynecol Rev Bras Gynecol Obstet. 2010;32(9):45968.

4. Araoye MO. Research Methodology with Statistics for Health and Social Sciences. Nathadex Publishers Ilorin; 2003: 115-129.

5. Duley L, Henderson-Smart DJ, Meher S. Drugs for treatment of very high blood pressure during pregnancy (Review). Cochrane Lib. 2007;4:1-78.

6. Tabasi Z, Oghbaee N, Samimi M, Sadat Z. Comparison between Effects of Intravenous Labetalol and Hydralazine on Control of Hypertension and Maternal and Neonatal Outcomes in Severe Preeclamptic Patients: A Randomized Clinical Trial. Qom Univ Med Sci J. 2012;6(4):44-9.

7. Delgado De Pasquale S, Velarde R, Rayes O, De La Ossa K. Hydrallazine vs Labetalol for the treatment of severe hypertensive disorders of pregnancy; A randomised controlled trial. Pregnancy Hypertens. 2014;4(1):19-22.

8. Nombur LI, Agida ET, Isah AY, Ekele BA. A comparison of Hydrallazine and Labetalol in the management of severe pre eclampsia. J Women Health care. 2014;3:6.

9. Deka Nabanita, Das Gokul Chandra, Baishya Swagata, Yadav Sangeeta. A comparative study of hydralazine versus labetalol in the management of pregnancy induced hypertension. Sch J App Med Sci. 2016;4(611B):3996-9.

10. Khan A, Hafeez S, Nasrullah FD. Comparison of Hydralazine and Labetalol to lower severe hypertension in pregnancy. Pak J Med Sci. 2017;33(2):466-70.

11. Mable WC, Gonzalez AR, Sibai BM, Amon E. A comparative trial of labetalol and hydralazine in the acute management of severe hypertension complicating pregnancy. Obstet Gynecol. 1987;70:328-33. 
12. Ashe RG, Moodley J, Richards AM, Philpott RH. Comparison of labetalol and dihydralazine in hypertensive emergencies of pregnancy. S Afr Med J. 1987;71:354-6.

13. Vigil-De Gracia P, Lasso M, Ruiz E, Vega-Malek JC, de Mena FT. Severe hypertension in pregnancy:hydralazine or labetalol. A randomized clinical trial. Eur J Obstet Gynecol Reprod Biol. 2006;128:157-62.
14. Magee LA, Cham C, Waterman EJ, Ohlsson A, Dadelszen PV. Hydralazine for treatment of severe hypertension in pregnancy: meta-analysis. BMJ. 2003;327(7421):955-60.

Cite this article as: Verma M, Gupta S, Bhagat BR, Mahajan A, Kaur B. Comparison of intravenous hydralazine and intravenous labetalol in the management of severe hypertensive disorders of pregnancy: a tertiary care centre study. Int J Reprod Contracept Obstet Gynecol 2018;7:2251-6. 